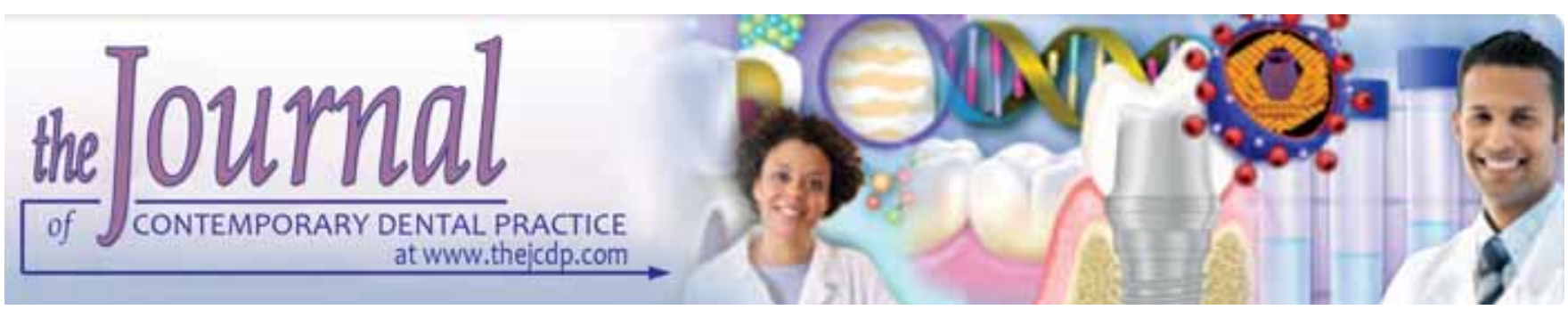

\title{
Dimensional Change of Elastomeric Materials after Immersion in Disinfectant Solutions for Different Times
}

Cintia lara Oda Carvalhal, José Antônio Nunes de Mello, Lourenço Correr Sobrinho, Américo Bertolazzo Correr Mário Alexandre Coelho Sinhoreti

\begin{abstract}
Aim: The aim of this study was to evaluate the influence of immersion period in two disinfectant solutions on dimensional change of four elastomeric impression materials.
\end{abstract}

Materials and methods: Four representative materials of each class of elastomers: Xantopren (polydimethylsiloxane-PDS), Express (polyvinyl siloxane-PVS); Permlastic (polysulfidePS) and Soft Impregum (polyether-EP) were mixed according to manufacturers' instructions and then inserted into a metal matrix prepared according to the specification of ISO 4823. The molds were removed from the matrix after 7 minutes and immersed in disinfectant solutions (sodium hypochlorite 0.5 and $2 \%$ glutaraldehyde) for $5,10,20,30$ and 60 minutes $(n=7)$, except the control group, which was not immersed. Once removed from solutions, the test samples were washed in water for 15 seconds, dried and measured three times, using a comparative optical microscope, with accuracy of $0.0005 \mathrm{~mm}$. The analysis of variance with three criteria and Tukey's test with significance level of $5 \%$ showed that differences in linear dimensions of the materials analyzed were not statistically significant $(p>0.05)$ after soaking in sodium hypochlorite 0.5 and $2 \%$ glutaraldehyde, for the tested periods of time.

Clinical significance: Combinations of molding material and disinfecting solution can be used in the dental clinic for infection control, without changing the dimensional molds, for immersion periods not longer than 20 minutes.

Keywords: Impression materials, Disinfectant solutions, Dimensional change, Elastomeric materials.

How to cite this article: Carvalhal $\mathrm{ClO}$, de Mello JAN, Sobrinho LC, Correr AB, Sinhoreti MAC. Dimensional Change of Elastomeric Materials after Immersion in Disinfectant Solutions for Different Times. J Contemp Dent Pract 2011;12(4): 252-258.

Source of support: Nil

Conflict of interest: None declared

\section{INTRODUCTION}

Several procedures expose the dentist and his team to the risk of direct or cross-contamination. ${ }^{1,2}$ Impression materials are used in dentistry for making accurate casts of the oral tissues, capable of recording the anatomic topography of the desired area and remaining dimensionally stable. During the impression procedure, the materials come into contact with oral fluids, such as blood, saliva, and other exudates and these may contain pathogenic microorganisms. Thus, through the impression, infectious diseases, such as herpes, hepatitis, tuberculosis, AIDS and others ${ }^{3-5}$ can be transmitted.

The disinfection of the mold is an important procedure, required in daily practice. Furthermore, it is an important biosafety measure in infection control in dental practice and can be defined as clinical stage designed to destroy a great part of microorganisms (viruses, bacteria and spores) from the surface of an impression. ${ }^{6}$

Due to the potential for infection and transmission of microorganisms in dental casts, it has been established that the molds should be washed in water to remove debris, blood and saliva, and then disinfected by immersion in chemical solutions that are compatible with the molding materials. ${ }^{7}$ Disinfection can be accomplished by physical or chemical action. However, physical action may result in temperature rise, which can cause measurable deformations in the molds. For impression materials the use of solutions with chemical action is recommended. The most frequently used are glutaraldehyde, formaldehyde, alcohol, iodine solution, synthetic phenol, sodium hypochlorite and other chlorinereleasing solutions.

Many dental professionals do not carry disinfection by immersion fearing dimensional change in impressions, especially in procedures that require high precision. ${ }^{8}$ Longer immersion times may negatively influence the dimensional stability of the molds. Some materials are more hydrophilic than others, and there may be different patterns of water absorption, which may undermine the stability of molds. ${ }^{9}$ Therefore, the time of immersion in disinfectant solutions 
is another factor that may undermine the stability of the molds, because the amount of water absorbed by the elastomeric material is time-dependent, which can lead to differences in the deformation of the impressions. ${ }^{10}$

Aware of the importance and complexity of the prevention of infectious diseases, and knowing that the dimensional accuracy and detail reproduction are important requirements for an impression used in making plaster casts and dies, the aim of this study was to evaluate the effect of immersion in two disinfecting solutions for different times in the dimensional changes of elastomeric molds.

\section{MATERIALS AND METHODS}

Materials used are described in Table 1.

The essay of dimensional change was carried in accordance with the standards of ISO 4823. To obtain the molds a metallic ring with outer diameter of $30 \mathrm{~mm}$ and $25 \mathrm{~mm}$ internal diameter was used. At the top surface of the matrix there were three parallel lines with $25 \mathrm{~mm}$ length and $2.5 \mathrm{~mm}$ distance between them, and two vertical lines marked with $x$ and $x^{\prime}$, which were used to verify the dimensional changes (Figs 1A to $\mathrm{H}$ ). Before performing the impression procedure, the matrixes were cleansed in an ultrasound device and dried with compressed air to remove any residue. The elastomeric impression materials were handled in accordance to the manufacturer's instructions.

\begin{tabular}{llll}
\multicolumn{4}{l}{ Table 1: Brand, type, manufacturer and batch of the materials } \\
\hline Brand & Type & Manufacturer & Batch \\
\hline Permlastic light & Polysulfide & Kerr & $7-1038$ \\
Impregum soft & Polyether & 3M Espe & 275177 \\
Xantopren VL & Polydimethyl- & Heraeus & 280055 \\
plus & siloxane & Kulzer & \\
Express light & Polyvinyl & 3M Espe & 6ANH1L1 \\
Body & siloxane & & \\
\hline
\end{tabular}

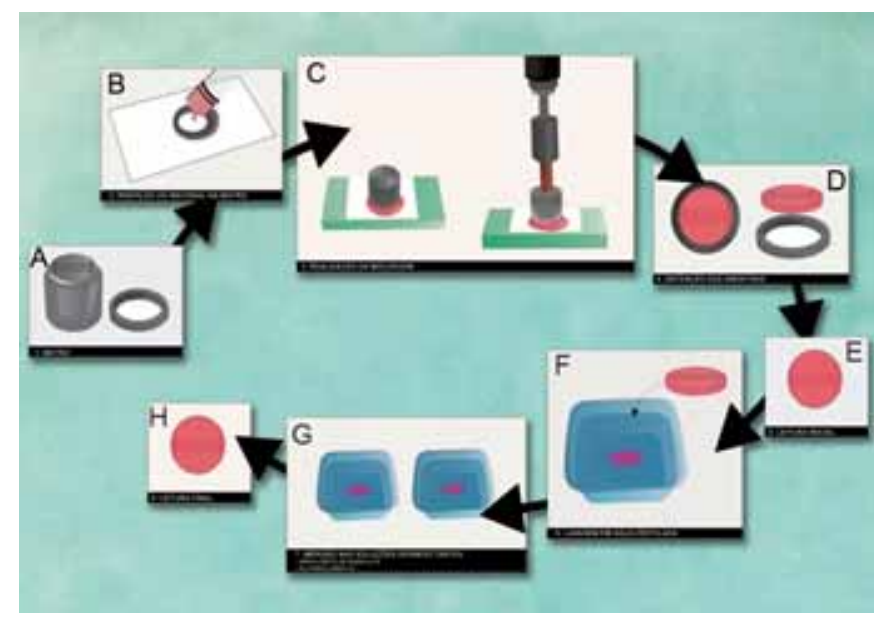

Figs $1 \mathrm{~A}$ to $\mathrm{H}$ : Schematic drawing of the applied methodology. (A) matrix; (B) insertion of the material in the matrix; (C) impression; (D) obtaining of samples; $(E)$ initial reading; $(F)$ rinsing in distilled water; $(G)$ immersion in disinfectant solution; $(H)$ final reading
A metal ring (30 mm inner diameter $\times 20 \mathrm{~mm}$ height) was placed on a glass plate and filled with the molding material. The matrix was coupled to the metal ring and a pressure of $2 \mathrm{kgf}$ (Wang et al 2007) was performed with the aid of a pneumatic press to simulate the impression and to allow leakage of excess material. To simulate the oral condition, the set (ring and matrix) was immediately immersed in distilled water at $37^{\circ} \mathrm{C}$. To ensure complete polymerization, the molds were removed 3 minutes past the minimum time recommended by the manufacturers of the materials. Around 126 bodies of proof for each material were made which were randomly separated into 18 groups $(\mathrm{n}=7)$, according to the disinfectant solution and immersion period:

- C0: No disinfectant, immediately

- C5: $100 \%$ relative humidity for 5 minutes

- C10: $100 \%$ relative humidity for 10 minutes

- C20: $100 \%$ relative humidity for 20 minutes

- C30: $100 \%$ relative humidity for 30 minutes

- C60: $100 \%$ relative humidity for 60 minutes

- H0: No disinfectant, immediately

- H5: Soaking in 0.5\% sodium hypochlorite for 5 minutes

- H10: Soaking in $0.5 \%$ sodium hypochlorite for 10 minutes

- H20: Soaking in $0.5 \%$ sodium hypochlorite for 20 minutes

- H30: Soaking in $0.5 \%$ sodium hypochlorite for 30 minutes

- H60: Soaking in $0.5 \%$ sodium hypochlorite for 60 minutes.

- G0: No disinfectant, immediately

- G5: Soaking in $2 \%$ glutaraldehyde for 5 minutes

- G10: Soaking in $2 \%$ glutaraldehyde for 10 minutes

- G20: Soaking in $2 \%$ glutaraldehyde for 20 minutes

- G30: Soaking in $2 \%$ glutaraldehyde for 30 minutes

- G60: Soaking in $2 \%$ glutaraldehyde for 60 minutes.

After the period of immersion, the bodies of proof were rinsed with $150 \mathrm{ml}$ of distilled water, dried and evaluated for dimensional accuracy. All measurements of dimensional change were performed by an operator with the aid of an optical microscope (STM-Olympus Optical Co Ltd, Japan) with an accuracy of $0.0005 \mathrm{~mm}$. The calculation in percentage of dimensional change was made in accordance with ISO 4823, using the equation:

$$
\mathrm{L}=\frac{(\mathrm{L} 2-\mathrm{L} 1)}{\mathrm{L} 1} \times 100
$$

Where L1 is the distance between the lines on the matrix and $\mathrm{L} 2$ is the distance between the lines on the impression material.

The data of dimensional change (\%) were subjected to analysis of variance two factors (material, disinfectant), and the immersion time factor treated as repeated measurements. 
Means were compared by Tukey's test with significance level of $5 \%$.

\section{RESULTS}

The results of analysis of variance showed difference among the three factors and interaction between factors ( $\mathrm{p}<$ $0.00001)$. Table 2 shows the mean values of $\Delta \mathrm{L}(\%)$ of the dimensional changes of each material for impression immersed in different disinfecting agents at different times. Positive values $(+)$ indicate that the gap between point $\mathrm{x}$ and $\mathrm{x}^{\prime}$ on the mold was greater than the distance shown in the metal matrix, with expansion of the impression. However, negative values indicate contraction of the impression.

Comparing periods of immersion, xantopren samples showed that dimensional change (contraction) was significantly higher after 60 minutes compared with other periods. The lowest dimensional change was observed in the immediate period, and the dimensional change was significantly higher at each assessment period. These results were obtained for both samples immersed in disinfectant solutions and for samples of the control group ( $p<0.05$ ). Permlastic express also displayed significantly higher dimensional change (contraction) after 60 minutes compared with other periods $(\mathrm{p}<0.05)$. However, no significant difference between other periods was found ( $p>0.05$ ) except for the permlastic in control group, where time of 30 minutes showed greater change than in the immediate time ( $\mathrm{p}<0.05$ ). For impregum immersed in hypochlorite and glutaraldehyde after 60 minutes, there was dimensional change (expansion) significantly greater than 30 minutes, and the latter was higher than other groups, which did not differ among themselves. When the disinfectant was not used, the immersion period of 60 minutes showed higher dimensional change than the period of 5 minutes ( $p<0.05$ ). The other time periods did not differ $(p>0.05)$. Comparing materials within each immersion period, it was observed that for both solutions at immediate period of immersion, there was no statistical difference among the four materials $(p>0.05)$. The same was observed for the group without disinfectant at immediately and 5 minutes time. In the remaining periods of immersion, in general, the material xantopren showed statistically higher values of dimensional change (contraction), followed by permlastic (contraction), express (contraction and closer to zero) and impregum (expansion).

Comparison of the disinfectant solutions within each material showed that in the immediate period, there was no difference between the solutions and the control group. In periods of immersion in 5, 10 and 20 minutes, there was no statistically significant difference between the disinfectant solutions for materials express, impregum and permlastic.
For xantopren, only at period of 20 minutes there was no difference between the disinfectant solutions. In immersion periods of 5 and 10 minutes, the hypochlorite solution led to greater dimensional change than immersion in water or chlorine. For the soaking periods of 30 and 60 minutes, in general, sodium hypochlorite led to greater dimensional changes to the materials xantopren, express, permlastic (contraction) and impregum (expansion) compared with glutaraldehyde and immersion in water.

\section{DISCUSSION}

There are many variables that can influence the dimensional stability of impression materials. Among them is the contraction during the polymerization and expansion that may occur after immersion in disinfectant solutions. ${ }^{11}$

Clinically, we observe that there is great variation in immersion periods of impression in disinfectant solutions. Therefore, this study investigates the effect of immersion time on the dimensional changes of casts made of different commercial brands of each type of elastomeric material. Data analysis showed that all materials presented dimensional changes over time. In general, xantopren, permlastic and express displayed contraction after immersion in disinfectant solutions or storage in $100 \%$ relative humidity, while impregum showed expansion.

Addition silicones or polyvinyl siloxane (PVS) materials are considered to have the best performance among the impression materials used in dentistry. ${ }^{12,13}$ The optimal dimensional stability of these materials is due to its polymerization reaction by addition. In this reaction there are no by-products, provided that the correct proportions are maintained and that there are no impurities. ${ }^{14}$ Although the dimensional change of these materials is not significant, the results showed that after 60 minutes the molds showed contraction. Approximation of the monomer and the polymer chains occurs during polymerization. Due to this approach, there is a reduction of space between molecules, leading to contraction of the material. ${ }^{11}$ This polymerization shrinkage also depends on the amount of filler particles added to the material. ${ }^{15}$

When immersed in disinfectant solutions, express had less shrinkage after 60 minutes compared with the control group. Although PVS is hydrophobic by nature, this material has the addition of surfactants in order to improve its ability to reproducing details in an environment with high humidity. ${ }^{16}$ The presence of these agents improves the compatibility of hydrophilic PVS with water, but can also increase the sorption of water when the impressions are immersed for long periods (60 minutes) in disinfectant solutions ${ }^{17}$ (Fig. 2). In this study, it is assumed that the sorption of water was somehow beneficial because it 


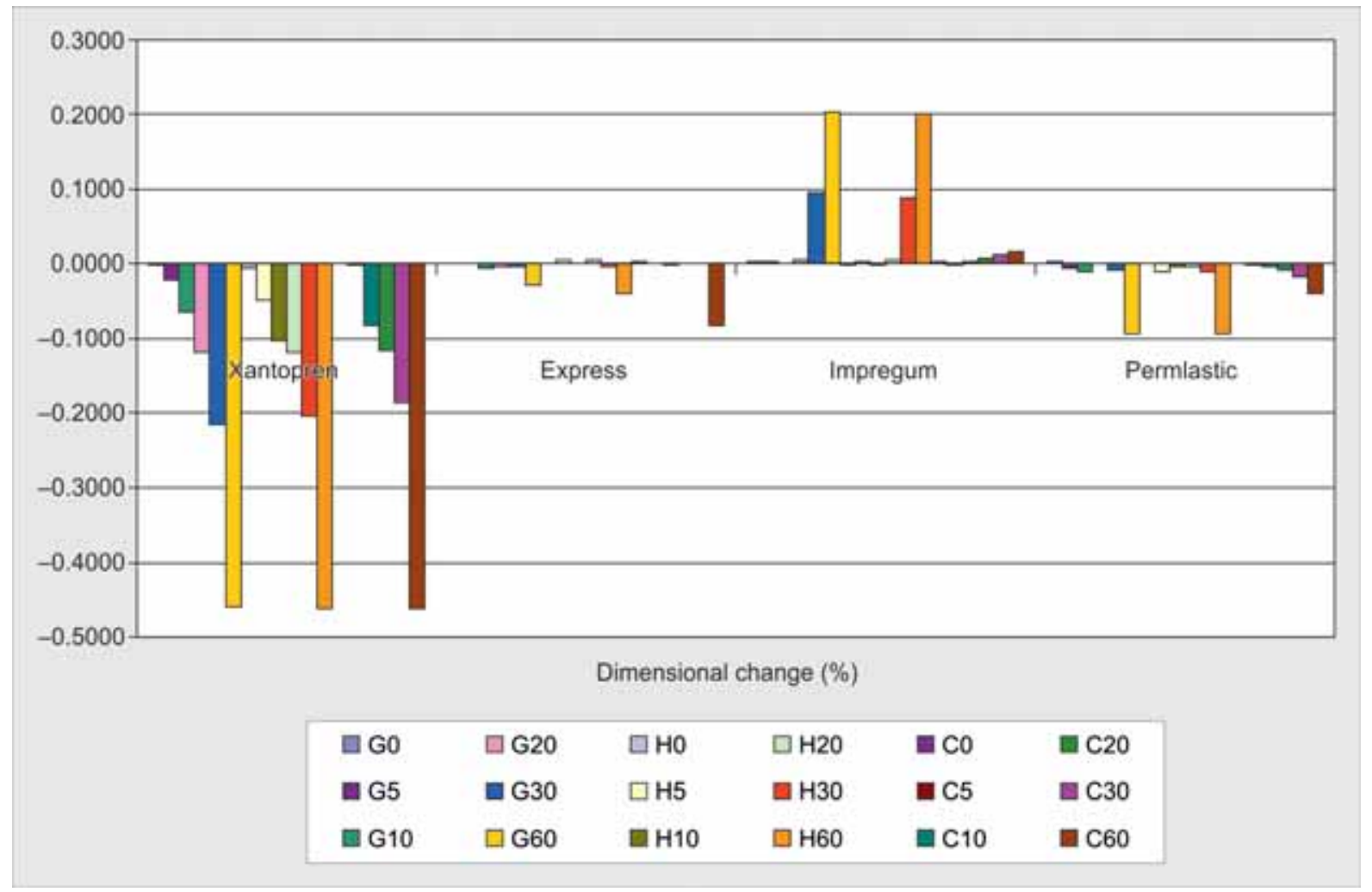

Fig. 2: Dimensional change of materials after immersion in disinfectant solutions for different periods of time

compensated, in part, the contraction of the material presented during the polymerization reaction. However, reports indicate that water absorption by the material is not homogeneous, which may cause distortions in the impression. ${ }^{18}$

Regarding polysulfide (permlastic), in addition to contraction due to reduced space that occurred during polymerization reaction, presents water as its by-product. The water is formed as a by product of the condensation reaction of molecules and can be lost through evaporation on the surface of the material. ${ }^{11}$ Polysulfides and polyethers are the elastomers that can be considered hydrophilic. They contain functional groups that attract and interact chemically with water molecules through hydrogen. ${ }^{19}$ The nature of the hydrophilic polyether groups is manifested in the carbonyl $(\mathrm{C}=\mathrm{O})$ and ether (COC) groups, while the hydrophilic groups of polysulfide are disulfide (-SS-) and mercapto (-SH) groups. ${ }^{19}$ However, it was observed in this study that the samples of polysulfide (permlastic) stored in sanitizing solution, showed greater contraction compared with control group after 60 minutes.

The material that showed the greatest contraction was condensation silicone or polydimethylsiloxane (PDS) $(\mathrm{p}<0.05)$. Unlike permlastic, the by-product of the condensation reaction of SP (xantopren) is ethyl alcohol. This explains the poor performance of this material over time, as the molecular weight of alcohol is higher than that of water, increasing the polymerization shrinkage. Furthermore, alcohol has a higher vapor pressure, facilitating its evaporation. Therefore, to ensure greater accuracy of the impressions obtained by condensation silicone, plaster cast should be prepared immediately after molding. ${ }^{10,19-23}$ Despite greater polymerization shrinkage, PDS is hydrophobic, being less susceptible to water sorption by immersion in disinfectant solutions. This can be seen in Table 2, which showed no difference between the groups immersed to the control group, which was not immersed.

In contrast to other types of materials investigated, the polyether material, impregum, expanded in all experimental situations. The polyethers are hydrophilic, ${ }^{20}$ and under conditions of high or absolute humidity, they absorb water, causing expansion of the mold and, consequently, distortion. ${ }^{24}$ Moreover, its setting mechanism occurs through a polymerization reaction of cationic addition with ring opening. The ionized form of sulfonic ether acid is the primary source of cations, and each stage of the reaction involves the opening of a ring epimine. Each molecule of prepolymer has two reactive groups of epimine. Therefore, individual propagation can produce chain elongation, causing expansion. ${ }^{14}$

The choice of disinfectant solutions used in this study ( $0.5 \%$ sodium hypochlorite and $2 \%$ glutaraldehyde) was due to the fact of its widespread effectiveness in the elimination of pathogens potentially present on the surfaces 
ฮี ન્ન

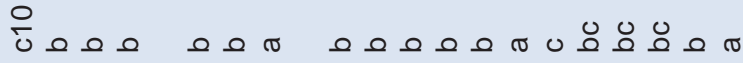

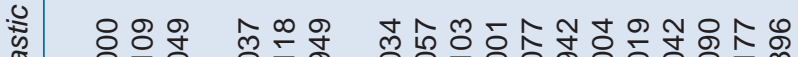
1.

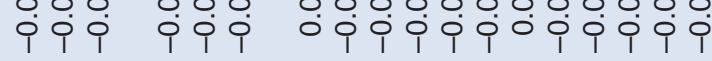

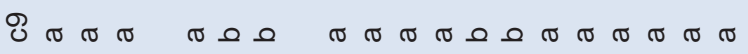

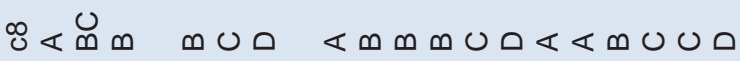

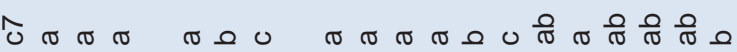

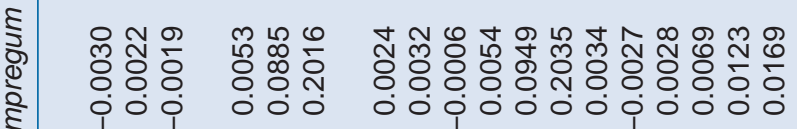

ర

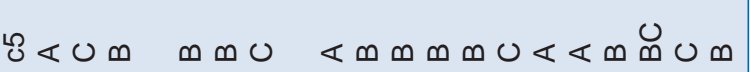
オ

ঋل ó0 0 ó

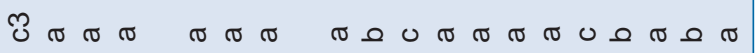

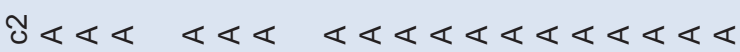
ป๋

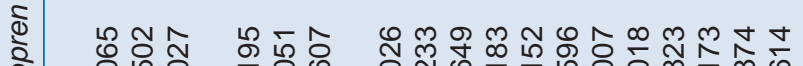

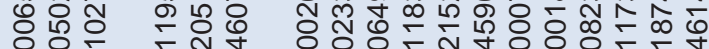

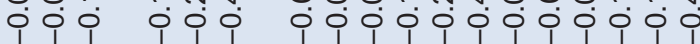
\begin{tabular}{llllllllll}
\hline & 1
\end{tabular}

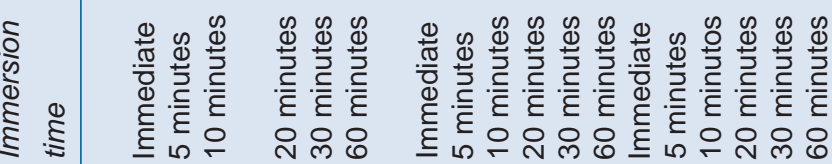
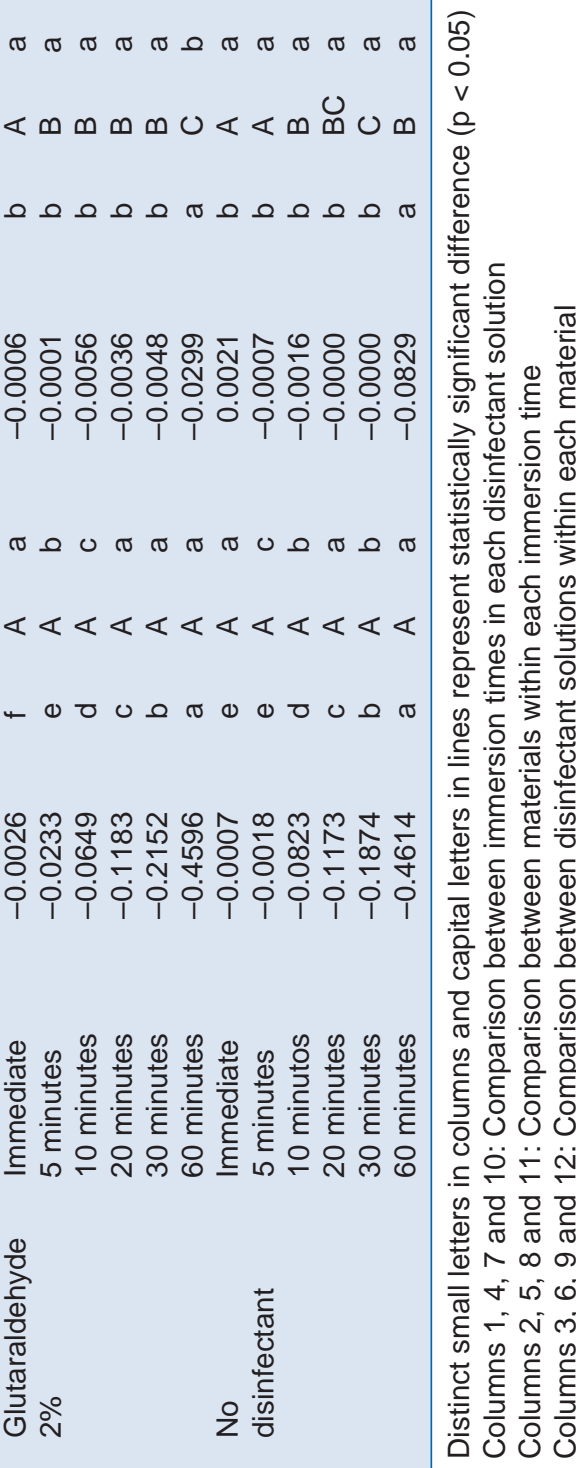
of impressions. ${ }^{2,25,26}$ It is observed in Table 1 that the samples immersed in $0.5 \%$ sodium hypochlorite and $2 \%$ glutaraldehyde showed similar patterns after different storage periods. These results agree with those reported in previous works, where no significant difference between the solutions used to disinfect molds polysulfide, polyether and PVS were found. ${ }^{3,27-29}$ For PDS (xantopren), the significant difference between the solutions in times of 5 and 10 minutes was probably related to leaching of alcohol in disinfecting solutions. However, after 30 minutes of immersion there was no difference between the solutions.

Dimensional changes around 0.1 to $0.8 \%$ are compensated at some stage during laboratory steps required in the preparation of the restorations. ${ }^{30}$ Despite the diversity of results in the literature on the effect of disinfectant solutions on the dimensional stability of elastomeric materials, it can be considered that the dimensional variations observed in this study are not sufficient to create significant distortions that can compromise the accuracy of prosthetic restorations.

\section{CONCLUSIONS}

Based on the obtained results, it can be concluded that:

- With the exception of polydimethylsiloxane for 5 or 10 minutes there were no differences between disinfectant solutions

- Immersion time influenced on dimensional change of different impression materials

- Up to 20 minutes, there was no significant dimensional change for impression materials.

\section{REFERENCES}

1. Guandallini SL. Bio Segurança. J Bras Orto Ortop Facial 1996;1:5-8.

2. Kimondollo PM. Guidelines for developing a dental laboratory infection-control protocol. Int J Prosthodont 1992;5:452-56.

3. Adabo GL, Zanarotti E, Fonseca RG, Cruz CA. Effect of disinfectant agents on dimensional stability of elastomeric impression materials. J Prosthet Dent 1999;81:621-24.

4. Minagi S, Kohada A, Akagawa Y, Tsuru H. Prevention of acquired immunodeficiency syndrome and hepatitis B (Part III): Disinfection of hydrophilic silicone rubber impression materials. J Prosthet Dent 1990;64:463-65.

5. Minagi S, Yano N, Yoshida K, Tsuru H. Prevention of acquired immunodeficiency syndrome and hepatitis B (Part II): Disinfection method for hydrophilic impression materials. J Prosthet Dent 1987;58:462-65.

6. Alves-Rezende MCR, Lorenzato F. Efeito de desinfecção por aerossóis sobre a capacidade de umedecimento de moldes de poliéter por gesso tipo IV. Rev Odont USP 1999;13:363-67.

7. Guidelines for infection control in the dental office and the commercial dental laboratory. Council on dental therapeutics. Council on prosthetic services and dental laboratory relations. J Am Dent Assoc 1985;110:969-72.
8. Muller-Bolla M, Lupi-Pegurier L, Velly AM, Bolla M. A survey of disinfection of irreversible hydrocolloid and silicone impressions in European Union dental schools: Epidemiologic study. Int J Prosthodont 2004;17:165-71.

9. Owen CP, Goolam R. Disinfection of impression materials to prevent viral cross contamination: A review and a protocol. Int J Prosthodont 1993;6:480-94.

10. Craig RG, Urquiola NJ, Liu CC. Comparison of commercial elastomeric impression materials. Oper Dent 1990;15:94-104.

11. Anusavice KJ. Phillips materiais dentários (11th ed). Rio de Janeiro: Elsevier 2005.

12. Chen SY, Liang WM, Chen FN. Factors affecting the accuracy of elastometric impression materials. J Dent 2004;32:603-09.

13. Petrie CS, Walker MP, O’Mahony AM, Spencer P. Dimensional accuracy and surface detail reproduction of two hydrophilic vinyl polysiloxane impression materials tested under dry, moist, and wet conditions. J Prosthet Dent 2003;90:365-72.

14. Rubel BS. Impression materials: A comparative review of impression materials most commonly used in restorative dentistry. Dent Clin North Am 2007;51:629-42, vi.

15. Mandikos MN. Polyvinyl siloxane impression materials: An update on clinical use. Aust Dent J 1998;43:428-34.

16. Craig RG, Powers JM. Restorative Dental Materials. St Louis: Mosby, Inc. 2002.

17. Thouati A, Deveaux E, Iost A, Behin P. Dimensional stability of seven elastomeric impression materials immersed in disinfectants. J Prosthet Dent 1996;76:8-14.

18. Lepe X, Johnson GH. Accuracy of polyether and addition silicone after long-term immersion disinfection. J Prosthet Dent 1997;78:245-49.

19. Chong YH, Soh G, Setchell DJ, Wickens JL. Relationship between contact angles of die stone on elastomeric impression materials and voids in stone casts. Dent Mater 1990;6:162-66.

20. Kanehira M, Finger WJ, Endo T. Volatilization of components from and water absorption of polyether impressions. J Dent 2006;34:134-38.

21. McCabe JF, Carrick TE. Recording surface detail on moist surfaces with elastomeric impression materials. Eur J Prosthodont Restor Dent 2006;14:42-46.

22. Melilli D, Rallo A, Cassaro A, Pizzo G. The effect of immersion disinfection procedures on dimensional stability of two elastomeric impression materials. J Oral Sci 2008;50:441-46.

23. Podshadley AG, Dilts WE, Neiman R, Sawyer HF. Accuracy of a mercaptan rubber impression technique using a stock tray. J Am Dent Assoc 1971;83:1303-08.

24. Walker MP, Rondeau M, Petrie C, et al. Surface quality and longterm dimensional stability of current elastomeric impression materials after disinfection. J Prosthodont 2007;16: 343-51.

25. Memarian M, Fazeli MR, Jamalifar H, Azimnejad A. Disinfection efficiency of irreversible hydrocolloid impressions using different concentrations of sodium hypochlorite: A pilot study. J Contemp Dent Pract 2007;8:27-34.

26. Taylor RL, Wright PS, Maryan C. Disinfection procedures: Their effect on the dimensional accuracy and surface quality of irreversible hydrocolloid impression materials and gypsum casts. Dent Mater 2002;18:103-10.

27. Langenwalter EM, Aquilino SA, Turner KA. The dimensional stability of elastomeric impression materials following disinfection. J Prosthet Dent 1990;63:270-76. 
28. Tullner JB, Commette JA, Moon PC. Linear dimensional changes in dental impressions after immersion in disinfectant solutions. J Prosthet Dent 1988;60:725-28.

29. Yilmaz H, Aydin C, Gul B, et al. Effect of disinfection on the dimensional stability of polyether impression materials. J Prosthodont 2007;16:473-79.

30. Johnson GH, Chellis KD, Gordon GE, Lepe X. Dimensional stability and detail reproduction of irreversible hydrocolloid and elastomeric impressions disinfected by immersion. J Prosthet Dent 1998;79:446-53.

\section{ABOUT THE AUTHORS}

\section{Cintia lara Oda Carvalhal (Corresponding Author)}

Professor, Department of Dental Materials and Odontology University of State of Amazonas, Amazonas, Brazil, e-mail: odacarvalhal@yahoo.com.br

\section{José Antônio Nunes de Mello}

Professor, Department of Prosthodontics and Odontology, University of State of Amazonas, Amazonas, Brazil

\section{Lourenço Correr Sobrinho}

Professor, Department of Dental Materials and Restorative Dentistry Piracicaba Dental School, UNICAMP, São Paulo, Brazil

\section{Américo Bertolazzo Correr}

Professor, Department of Dental Materials and Restorative Dentistry Piracicaba Dental School, UNICAMP, São Paulo, Brazil

\section{Mário Alexandre Coelho Sinhoreti}

Professor, Department of Dental Materials and Restorative Dentistry Piracicaba Dental School, UNICAMP, São Paulo, Brazil 